\title{
STATIC THERMAL ANALYSIS OF FINS MODELS USING ANSYS
}

\author{
Rajat Kumar \\ Department of Mechanical Engineering, \\ Sachdeva Institute of Technology Farah Mathura Uttar Pradesh, \\ Dr. A.P.J. Abdul Kalam Technical University, Uttar Pradesh, India \\ Devendra Singh \\ Assistant Professor, Sachdeva Institute of Technology, \\ Farah Mathura, Uttar Pradesh, India \\ Ajay Kumar Sharma \\ Assistant Professor, Institute of Engineering and Technology, \\ Lucknow, Uttar Pradesh, India
}

\begin{abstract}
The Engine chamber is one of the essential engine components, that is subjected to over the top temperature differences and thermal stresses. Fins are set on the surface of the cylinder to improve the quantity of heat exchange by convection. When fuel is burned in an engine, heat is produced. Additional heat is also generated by friction between the moving parts. In air-cooled I.C engine, extended surfaces called fins are provided at the periphery of engine cylinder to increase heat transfer rate. That is why the analysis of fin is important to increase the heat transfer rate. The main of aim of this work is to study various researches done in past to improve heat transfer rate of cooling fins by changing cylinder fin geometry and material. In the present work, Experiments have been performed to discover the temperature variations inside the fins made in four kind geometries (plate Fins, Circular Pin fins, plate fins with holes, and draft Pin fins) and consistent state heat exchange examination has been studied utilizing a finite element software ANSYS to test and approve results. The temperature variations at various areas of fins models are evaluated by FEM and compared models of fins performance by heat flux and temperature variations obtained by experimentally in Analysis. The principle implemented in this project is to expand the heat dissipation rate by utilizing the wind flow. The main aim of the study is to enhance the thermal properties by shifting geometry, material, and design of fins.
\end{abstract}

Keywords: Heat transfer, extended surfaces, Thermal analysis, and FEM, Analysis and Heat transfer enhancement.

Cite this Article: Rajat Kumar, Devendra Singh and Ajay Kumar Sharma, Static Thermal Analysis of Fins Models Using Ansys. International Journal of Mechanical Engineering and Technology 11(2), 2020, pp. 10-21.

https://iaeme.com/Home/issue/IJMET?Volume $=11 \&$ Issue $=2$ 


\section{INTRODUCTION}

In normal cause, larger parts of an engine remain exposed to the atmospheric air. When the vehicles run, the air at certain relative velocity impinges upon the engine, and sweeps away its heat. The heat carried-away by the air is due to natural convection, therefore this method is known as natural air-cooling. Engines mounted on 2-wheelers are mostly cooled by natural air. As the heat dissipation is a function of frontal cross-sectional area of the engine, therefore there exists a need to enlarge this area. An engine with enlarge area will becomes bulky and in turn will also reduce the power by weight ratio. Hence, as an alternative arrangement, fins are constructed to enhance the frontal cross-sectional area of the engine. Fins (or ribs) are sharp projections provided on the surfaces of cylinder block and cylinder head. To avoid overheating, and the consequent ill effects, the heat transferred to an engine component (after a certain level) must be removed as quickly as possible and be conveyed to the atmosphere. The heat exchange from surfaces may, in general, be enhanced by expanding the heat exchange coefficient between a surface and its environment, by expanding the heat exchange zone of the surface, or by both. In most cases, the region of Heat exchange is expanded by using extended surfaces as balances the fins joined to walls and surfaces. Expanded surfaces (fins) are much of the time utilized in heat exchanging devices to increase the heat exchange between an essential surface and the surrounding liquid. Different types of fins, going from moderately simple geometries to complex geometries have been utilized. A shape of the regular fins geometries is rectangular, triangular, cylindrical, trapezoidal etc. For the guideline of conduction, convection, radiation of a fin arrangement optimized the quantity of heat it exchanges Increasing the temperature contrast between the fin setup and based upon surroundings, marginally expanding the convection heat transfer coefficient, or somewhat expanding the surface region of the fin design of the object enhance the heat exchange. This can be achieved by faster heat dissipation. By using the extended surfaces (Fins) we can improve the heat transfer rate from engine cylinder. For this analysis of the heat transfer rate of the fins is imperative. Every combination of shape, size and material have their own efficiency thereby selecting the best possible combination which give maximum efficiency to get required heat transfer rate for maximum engine efficiency. Extended area on the cylinder surfaces is use to increase the surface area in contact with the fluid flowing around it.

\section{EXTENDED SURFACES (FINS)}

In the Heat exchange study, the surface that extruded out from a base is known as a fin. fins are utilized to enhance the rate of heat dissipation from or to the environment by expanding the rate of convection. The all of convection, conduction, or radiation of an object chooses the rate of heat it transferred. It increments with the distinction of temperature between surroundings and the object, additionally expanding the convection coefficient of heat exchange, or expanding the surface region. But, increase of the area also causes increased resistance to the heat flow. Hence, coefficient of heat transfer is based on the total area (the base and fin surface area) which comes out to be less than that of the base. There are different types of shape and size fins used in engineering applications to increasing the heat transfer rate such as

- Rectangular fins

- Triangular fins

- Trapezium fins

- Circular segmental fins.

Different shape and designs of fins are used in different situations. 


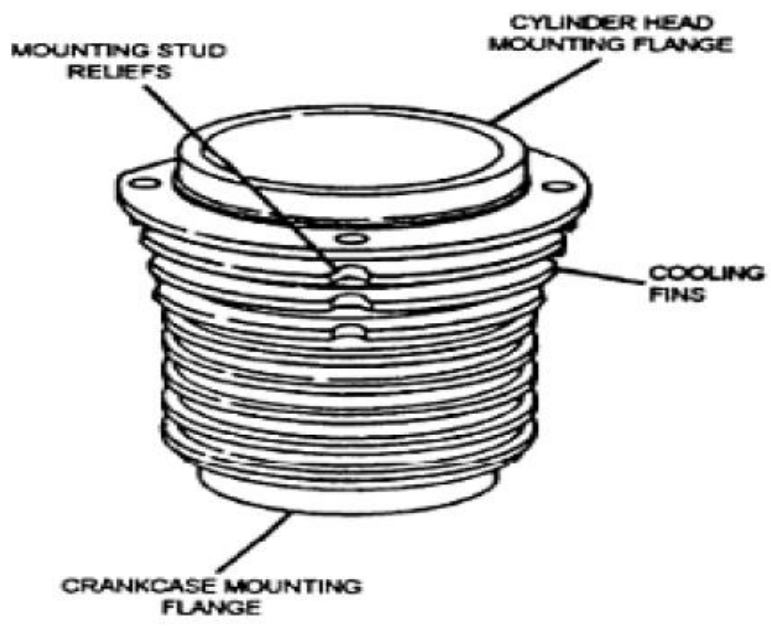

Figure 1 Cylinder with fins

(Source: Ahirwar et al. 2018).

\section{MATERIAL PROPERTIES OF FINS MATERIAL}

Thermal analysis of Fins performed by using Aluminum alloy of the Fins material. Composition of Aluminum alloy is shown in Table 1.

Table 1: Material properties of Fins Model

\begin{tabular}{|l|c|c|}
\hline \multicolumn{1}{|c|}{ Parameters } & Unit & $\begin{array}{c}\text { Aluminum alloy } \\
(\mathbf{1 0 6 0})\end{array}$ \\
\hline Density & $\left(\mathrm{Kg} / \mathrm{m}^{3}\right)$ & 2700 \\
\hline Young's Modulus & $(\mathrm{MPa})$ & 69000 \\
\hline Coefficient of thermal expansion & $(1 / \mathrm{K})$ & $2.3 \times 10^{-5}$ \\
\hline Poisson's Ratio & - & 0.33 \\
\hline Elastic modulus & $(\mathrm{GPa})$ & 70 \\
\hline Ultimate Tensile Strength & $(\mathrm{MPa})$ & 310 \\
\hline Thermal conductivity & $\left(\mathrm{W} / \mathrm{m} /{ }^{\circ} \mathrm{C}\right)$ & 200 \\
\hline
\end{tabular}

\section{DESIGN AND ANALYSIS OF FINS}

\subsection{Modeling of Fins Model}

Fins models designed with the material selection of aluminum alloy 1060 and three Fins model designed here i.e. plate Fins, Circular Pin fins and Rectangular pin fins. Fins model with plate fins and pin fins in type of circular and rectangular holes pin fins fins for passing air through fins. FEM analysis performed through Ansys. The practical use of finite element modeling is known as FEA which is best understood during the real problem solving. FEA has been broadly utilized by the automotive business. It is an extremely prominent instrument for configuration builds in the product development technique. It is imperative to comprehend the FEA basics and design technique, demonstrating systems, the inherent mistakes and their impacts on the nature of the outcomes to render FEA as an effective design tool. FEA is also used as a computational tool for carrying out engineering problem analyses. 
Static Thermal Analysis of Fins Models Using Ansys
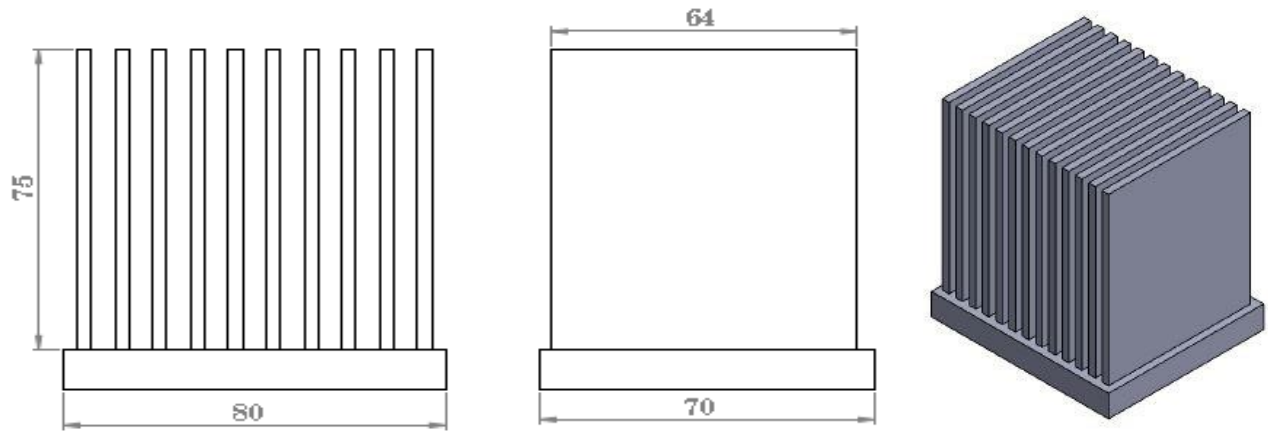

Figure 2: Plate Fins Designed Model in Ansys

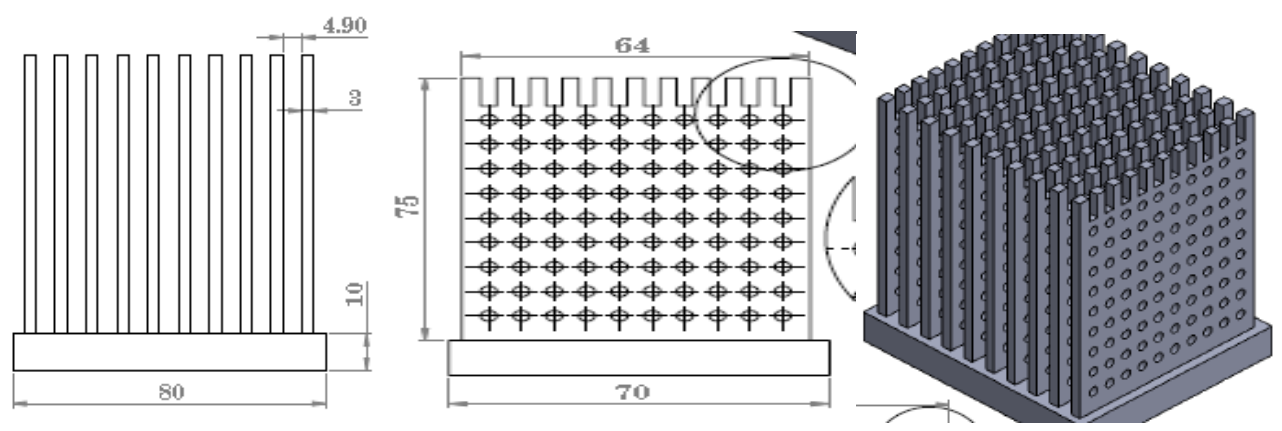

Figure 3: Rectangular Pin Fins Designed Model in Ansys
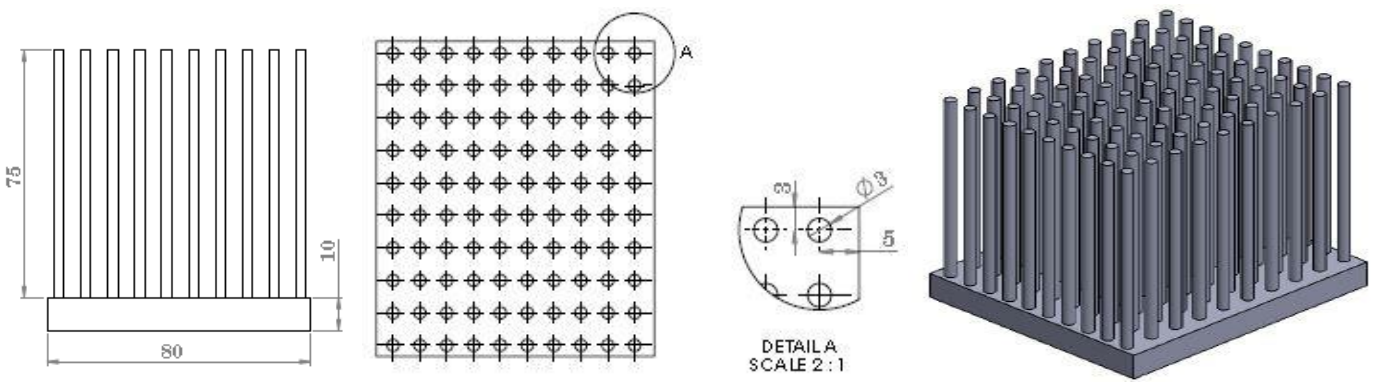

Figure 4: Circular Pin Fins Designed Model in Ansys
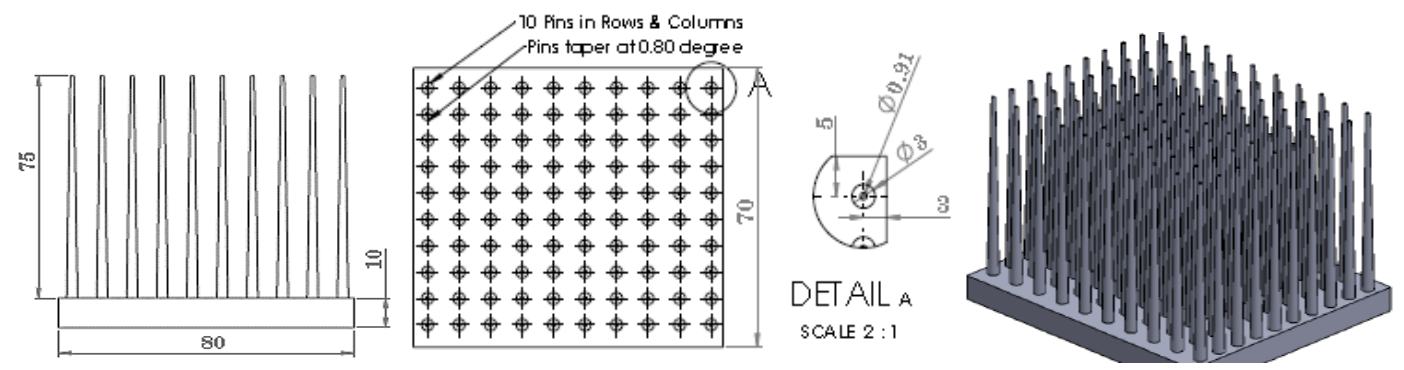

Figure 5: Draft Pin Fins Designed Model in Ansys

\subsection{Applying Boundary Conditions}

Figure represents the applied boundary conditions on Fins Model has Heat Flow 13 W, and convection conditions $22{ }^{\circ} \mathrm{c}$ while convection on the top surface of the Fins has been applied, to optimize Maximum and minimum temperature also optimize maximum heat flow rate for high heat transfer. Figure shows the applied boundary conditions of Fins Model. 
Rajat Kumar, Devendra Singh and Ajay Kumar Sharma

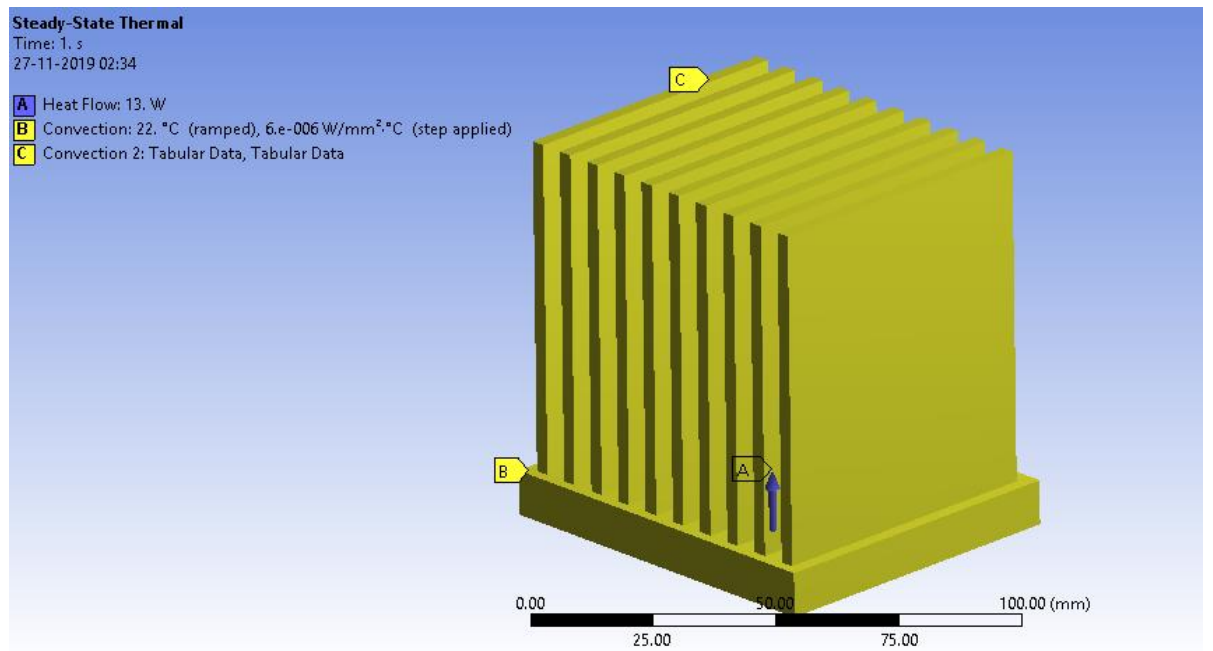

Figure 6: Applied Boundary conditions on Plate Fins

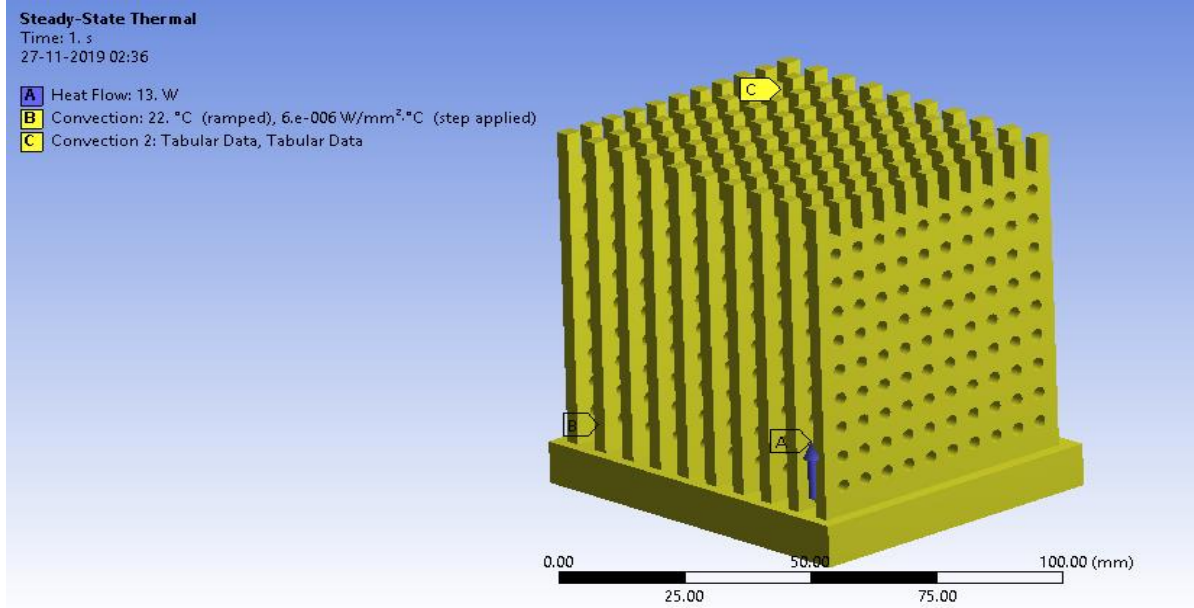

Figure 7: Applied Boundary conditions on Rectangular plate Fins with holes

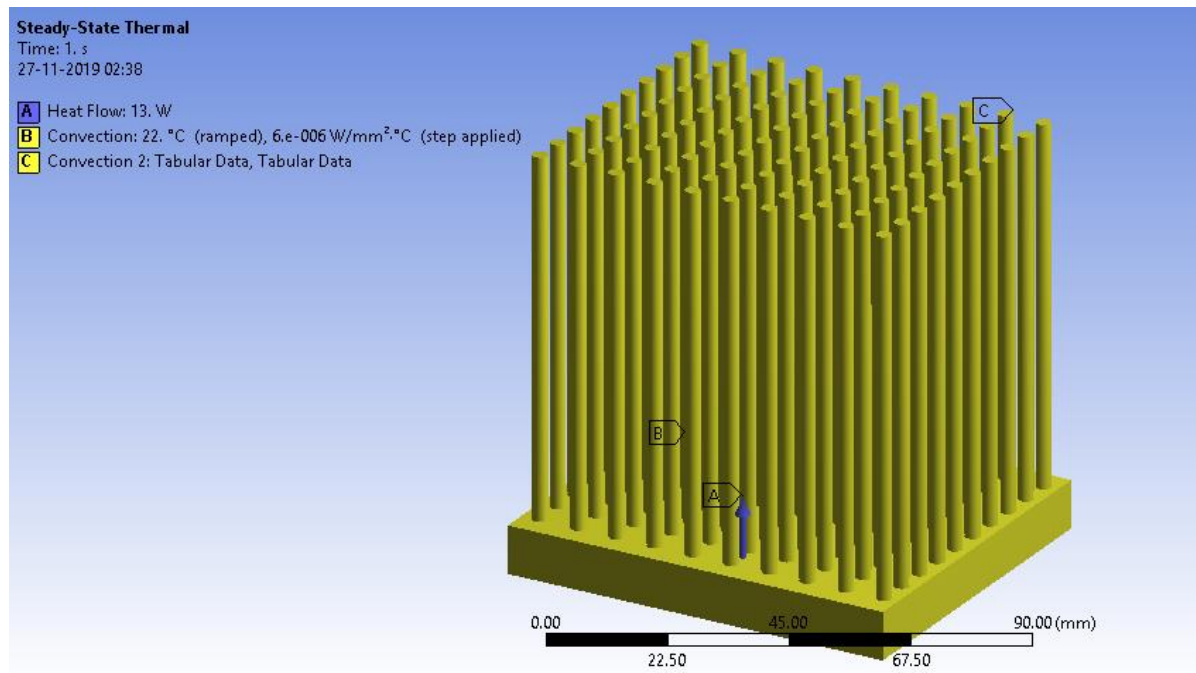

Figure 8: Applied Boundary conditions on Circular Pin Fins 


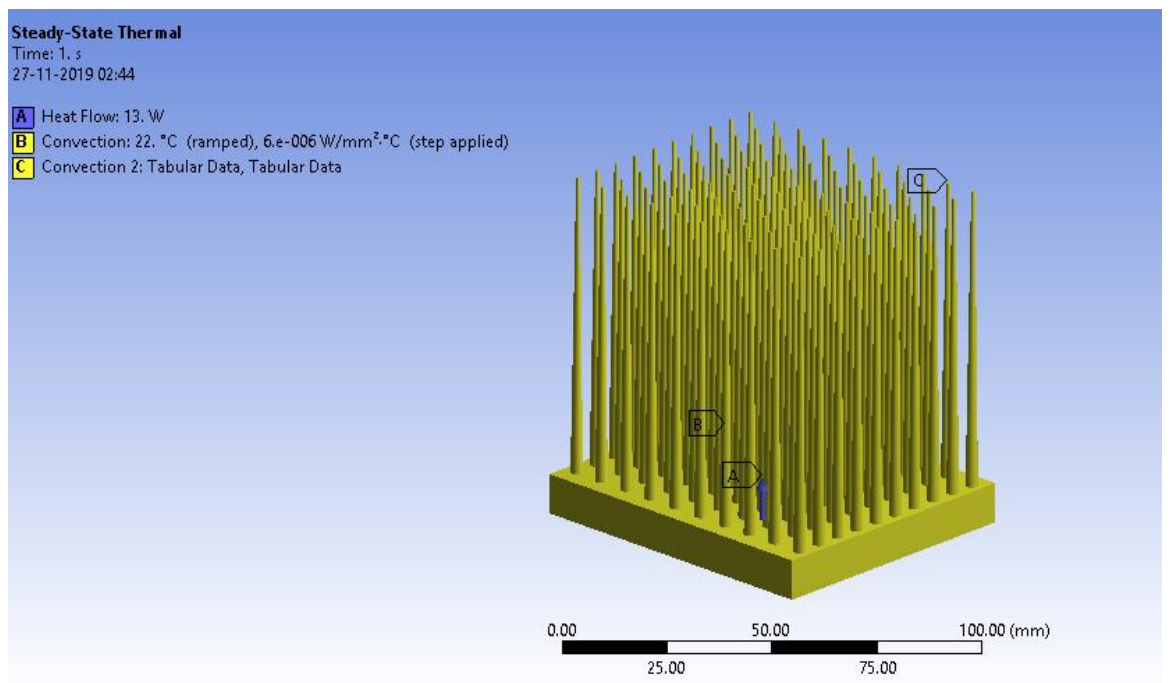

Figure 9: Applied Boundary conditions on Draft conical Pin Fins

\section{RESULTS AND DISCUSSION}

The Fins model to research is subdivided into a mesh of limited measured components of the basic frame. Inside every segment, the distinction of displacement is thought to be computed by basic polynomial profile capacities and nodal Temperature. Conditions for the strains and stresses are created as far as the obscure nodal temperature. From this, the conditions of balance are collected in a grid shape which can be easily customized. Temperature variation across various Finsmodels in steady state condition shows and boundary conditions applied shown in figures Maximum temperature at top. After processing solution, the Temperature and Total Heat Flux in thermal analysis compared with the plate Fins, Circular Pin fins, and plate fins with holes, draft Pin fins. These results as part of structural and thermal analysis are obtained for all three conditions i.e. plate Fins, Circular Pin fins, plate fins with holes, and draft Pin fins. Figures shows the simulation study in Ansys of Fins models.

\section{Temperature Distribution Analysis of Fins Models}

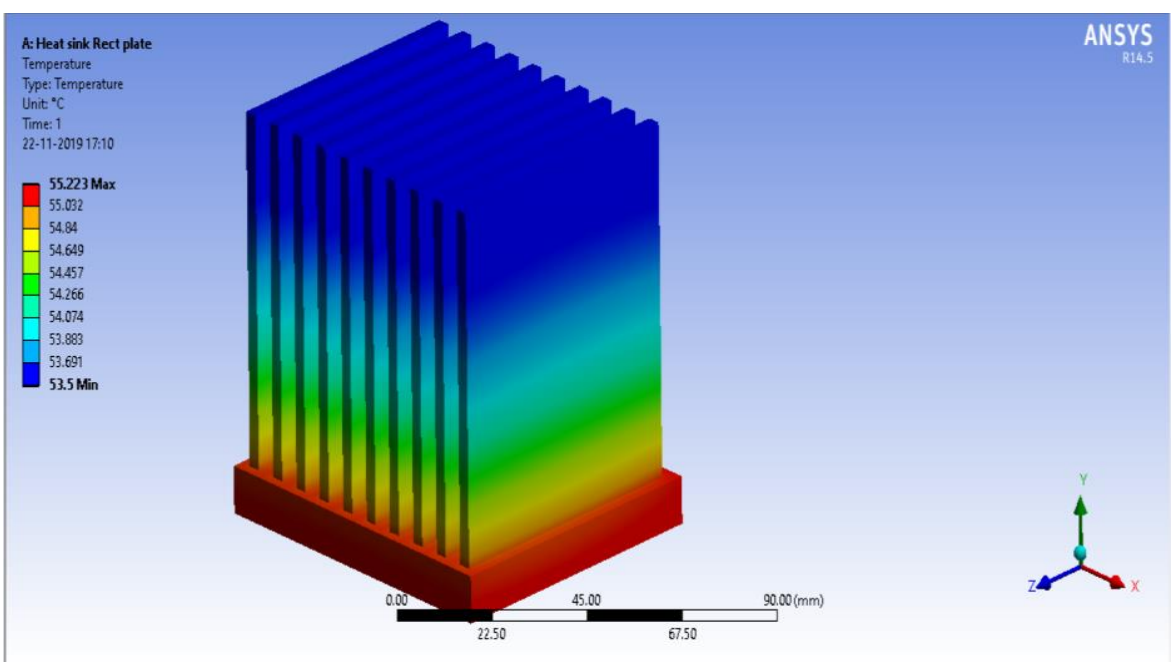

Figure 10: Temperature Distribution of Plate Fins 
Rajat Kumar, Devendra Singh and Ajay Kumar Sharma

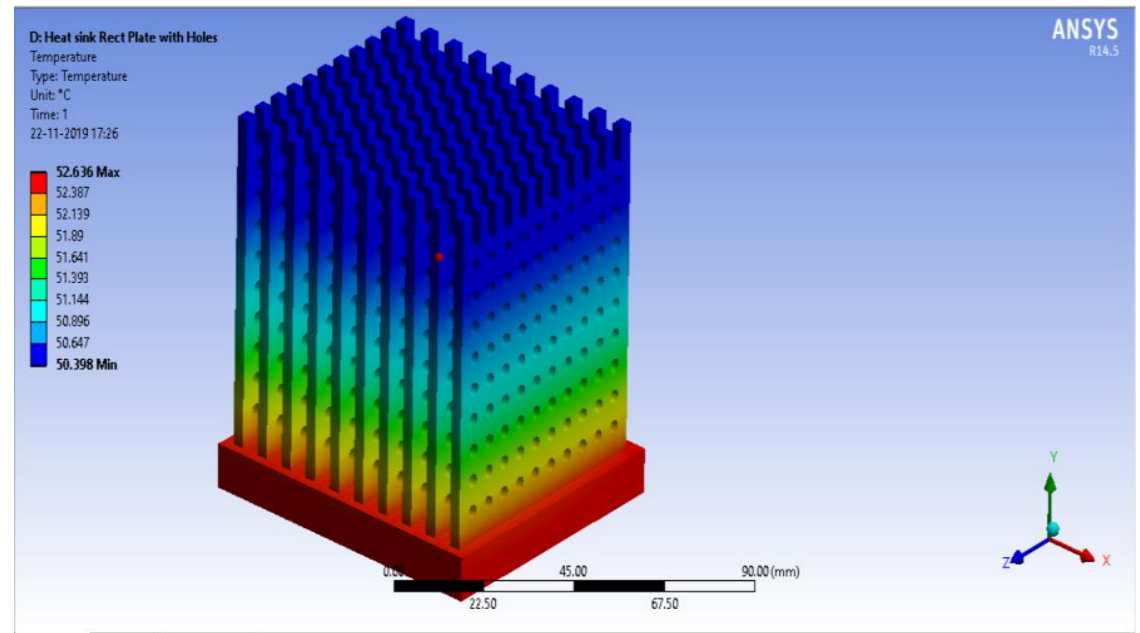

Figure 11: Temperature Distribution of Rectangular plate Fins with holes

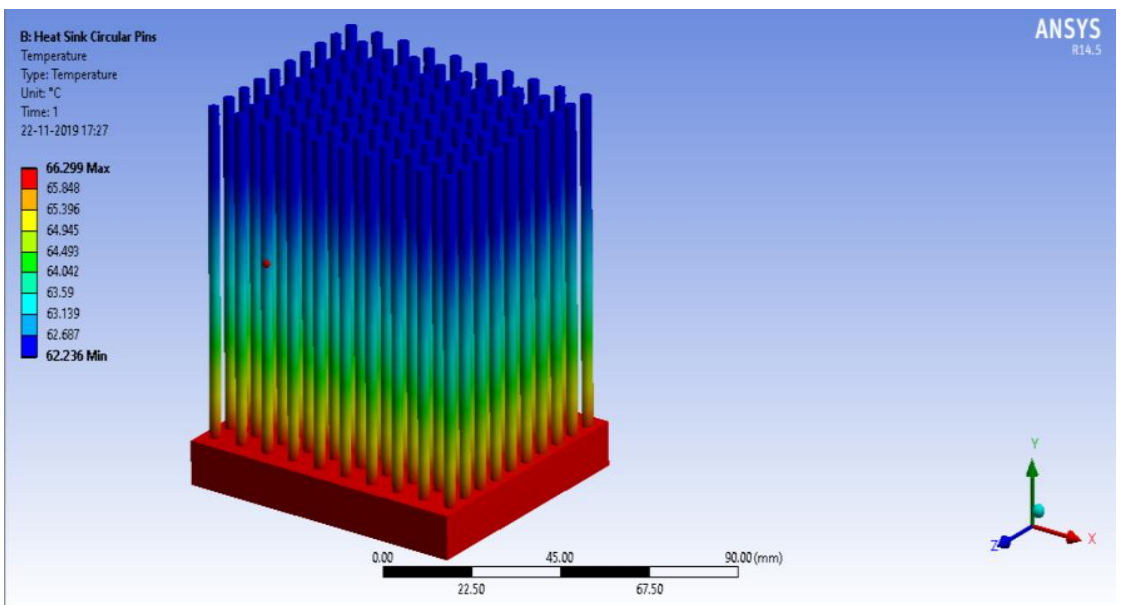

Figure 12: Temperature Distribution of Circular Pin Fins

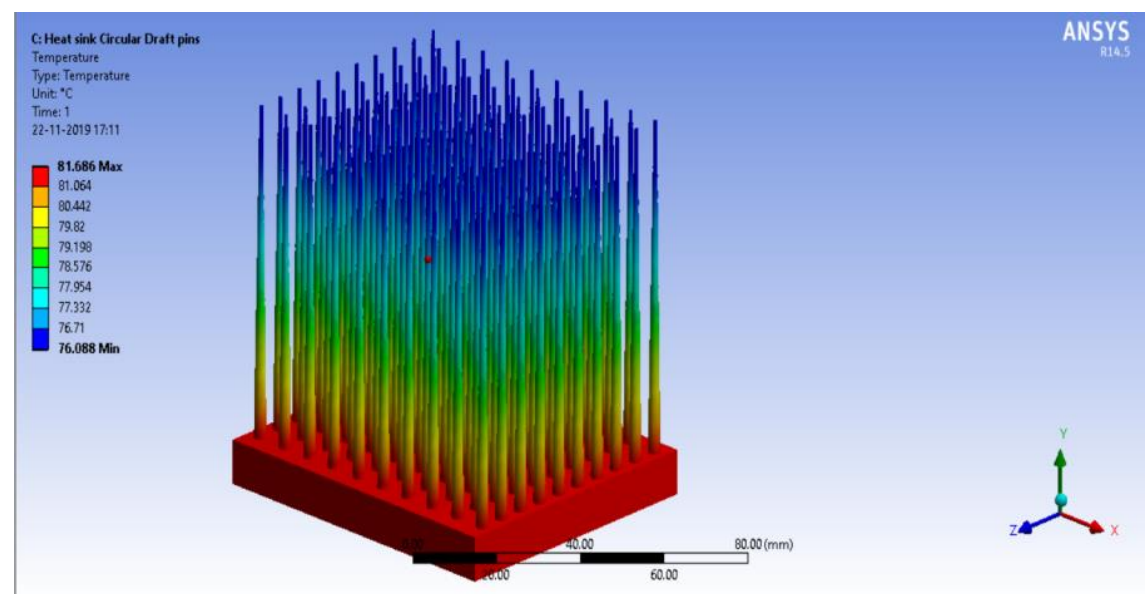

Figure 13: Temperature Distribution of draft conical Pin Fins 


\section{Heat Flux and Stress Analysis of Fins Models}

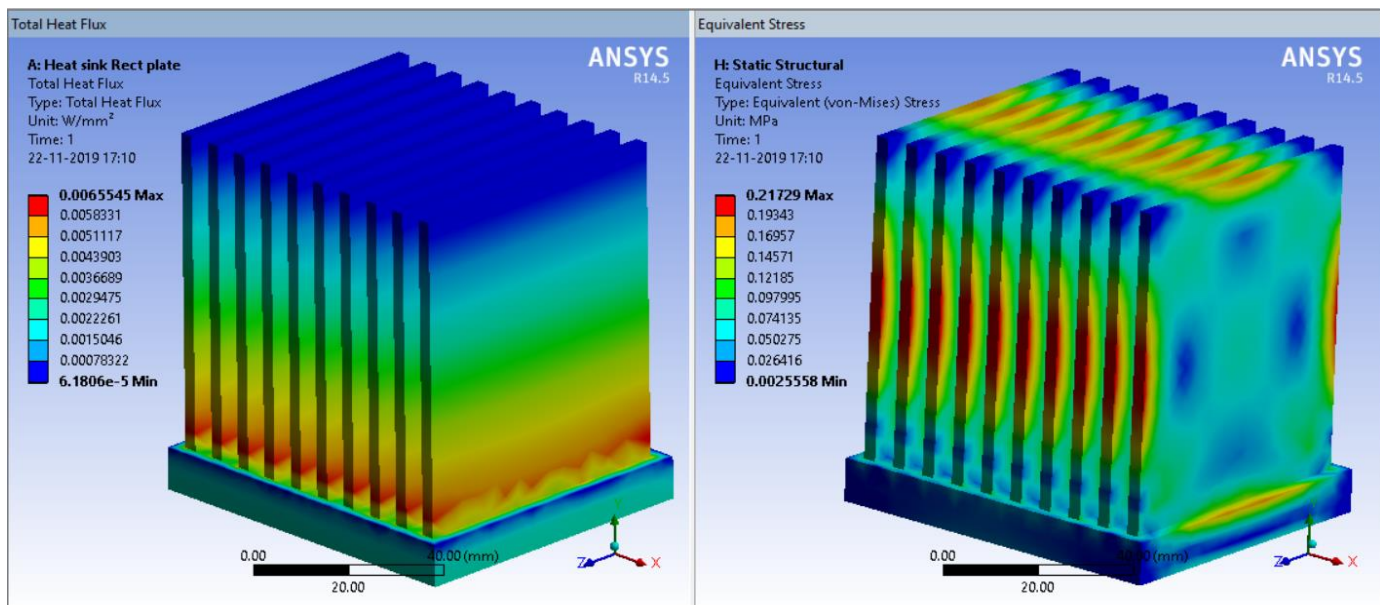

Figure 14: Heat Flux and Stress of Plate Fins
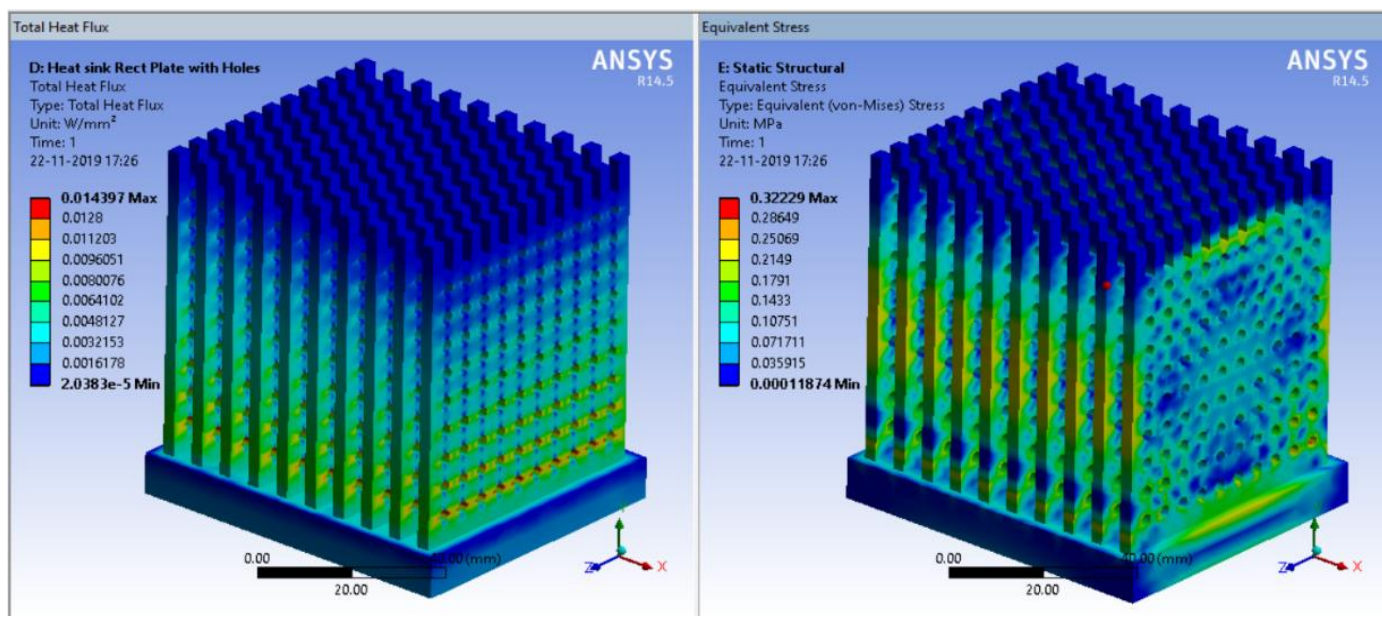

Figure 15: Heat flux of Rectangular plate Fins with holes

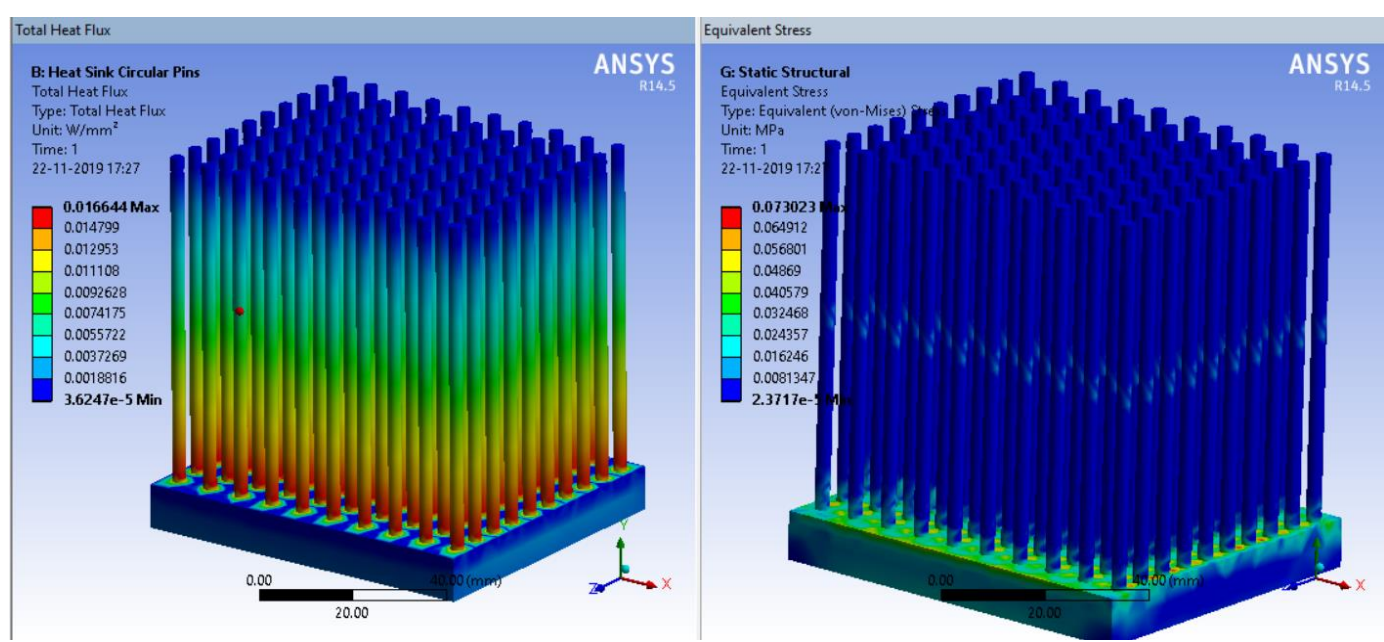

Figure 16: Heat fluxand Stress of Circular Pin Fins 
Rajat Kumar, Devendra Singh and Ajay Kumar Sharma

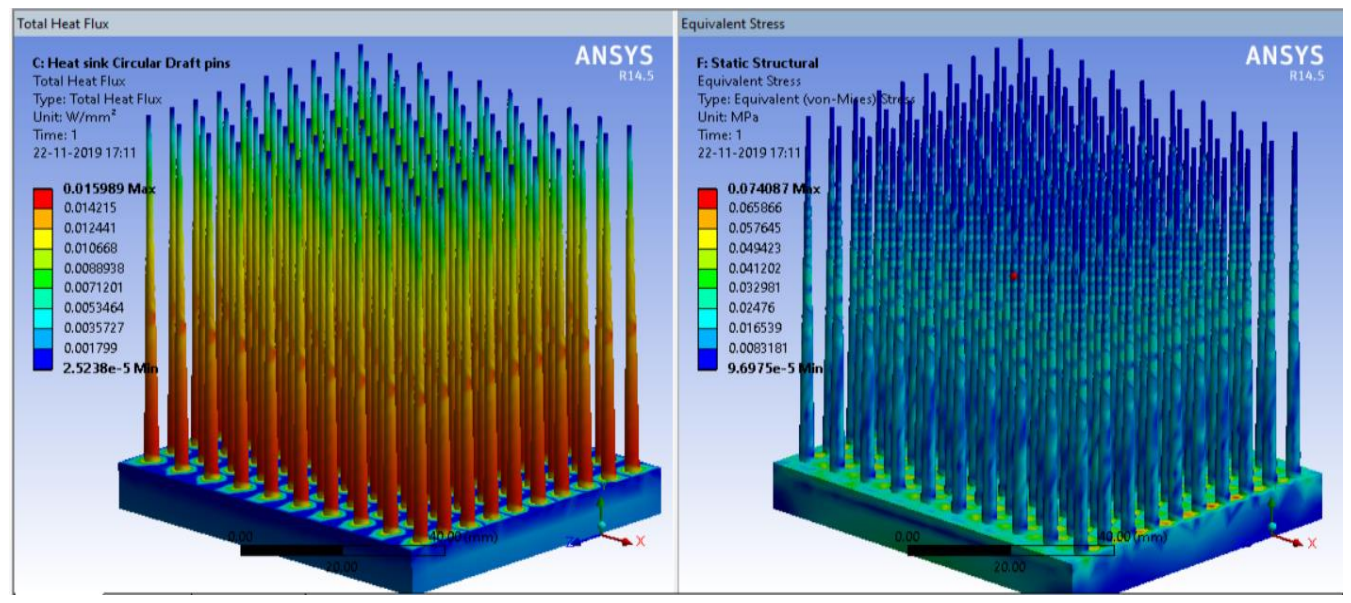

Figure 17: Heat flux and Stress of Circular Pin Fins

Table 2: Temperature Variations of Fins Models

\begin{tabular}{|l|c|c|c|c|}
\hline \multicolumn{1}{|c|}{ Geometry Condition } & Heat Flow(watt) & $\begin{array}{c}\text { Max } \\
\text { Temperature } \\
\left({ }^{\circ} \mathbf{C}\right)\end{array}$ & $\begin{array}{c}\text { Min } \\
\text { Temperature } \\
\left({ }^{\circ} \mathbf{C}\right)\end{array}$ & $\begin{array}{c}\text { Temperature } \\
\mathbf{d r o p}\left({ }^{\circ} \mathbf{C}\right)\end{array}$ \\
\hline fins with rectangular plate & 13 & 55.22 & 53.5 & 1.72 \\
\hline Circular pin fins & 13 & 66.29 & 62.23 & 4.06 \\
\hline Conical draft pin fins & 13 & 81.68 & 76.08 & 5.6 \\
\hline $\begin{array}{l}\text { Rectangular plate fins with } \\
\text { holes }\end{array}$ & 13 & 52.63 & 50.39 & 2.24 \\
\hline
\end{tabular}

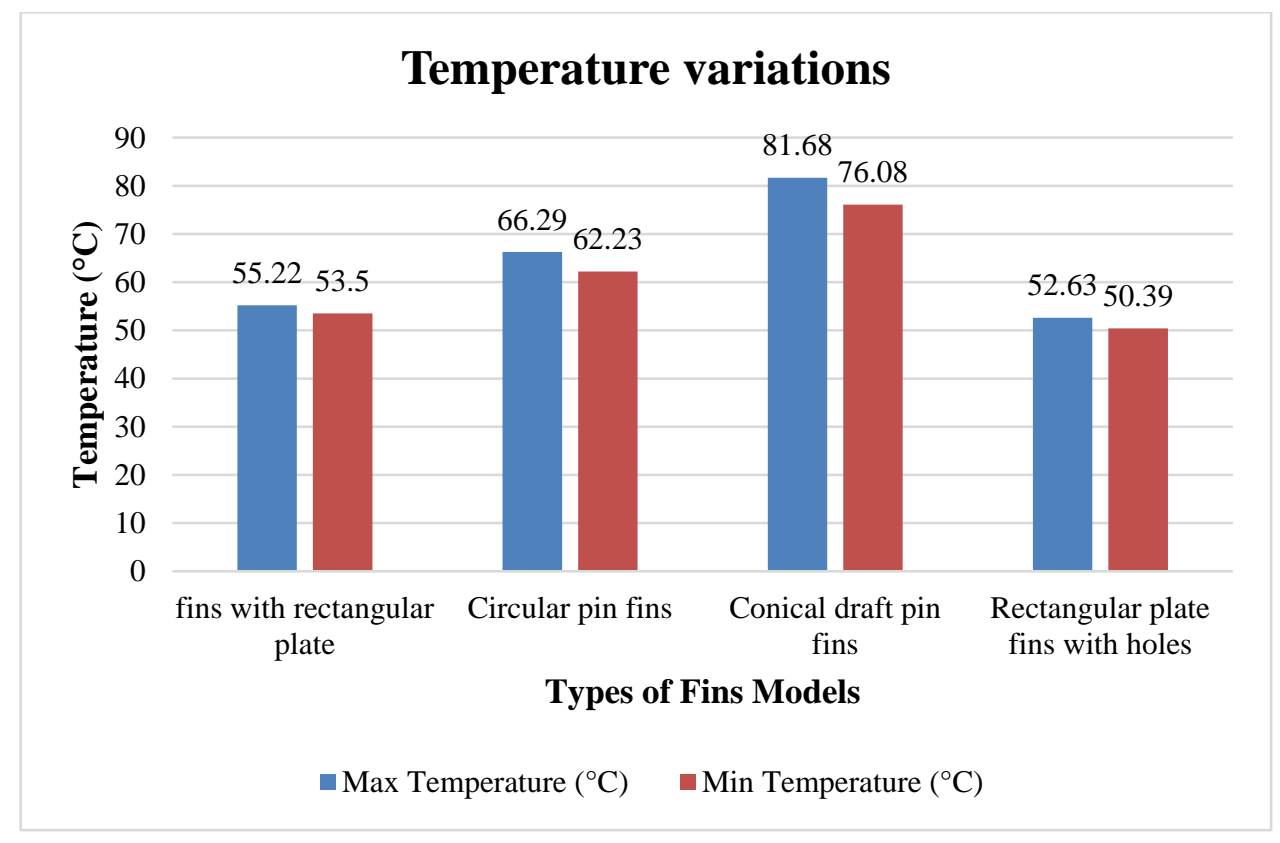

Figure 18: Temperature Variationsin Models of Fins 


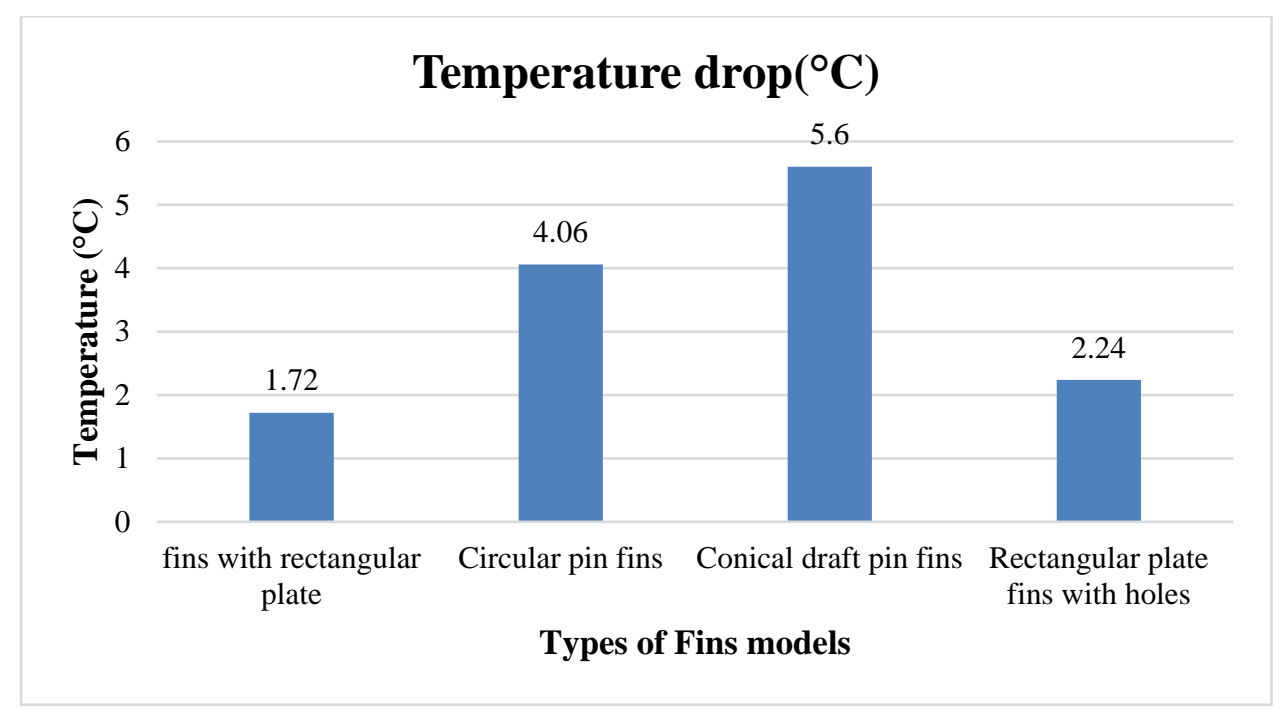

Figure 19: Total Temperature Drop in Fins Models

Table 3: Heat Flux Found on All conditions of Fin Models

\begin{tabular}{|l|c|c|c|}
\hline \multicolumn{1}{|c|}{ Geometry Condition } & Heat Flux & $\begin{array}{c}\text { Thermal } \\
\text { Stress(MPa) }\end{array}$ & Weight(kg) \\
\hline fins with rectangular plate & 0.0065 & 0.217 & 0.554 \\
\hline Circular pin fins & 0.016 & 0.073 & 0.301 \\
\hline Conical draft pin fins & 0.015 & 0.074 & 0.223 \\
\hline Rectangular plate fins with holes & 0.014 & 0.322 & 0.48 \\
\hline
\end{tabular}

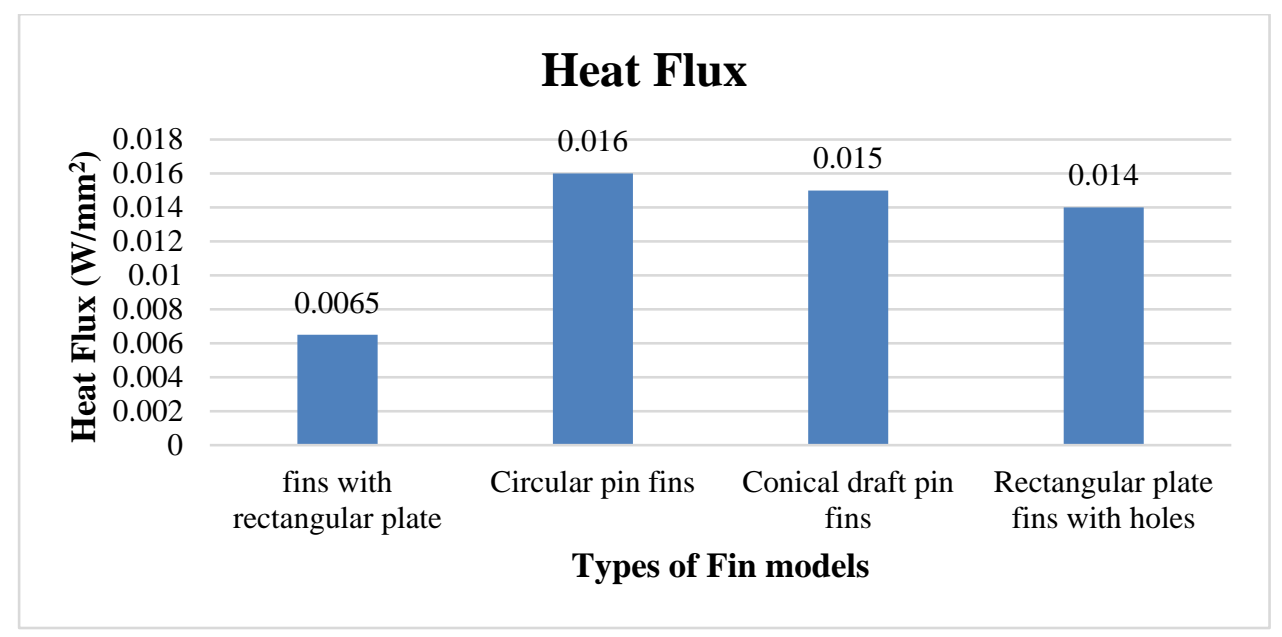

Figure 20: Comparison of Heat flux of Fin Models 


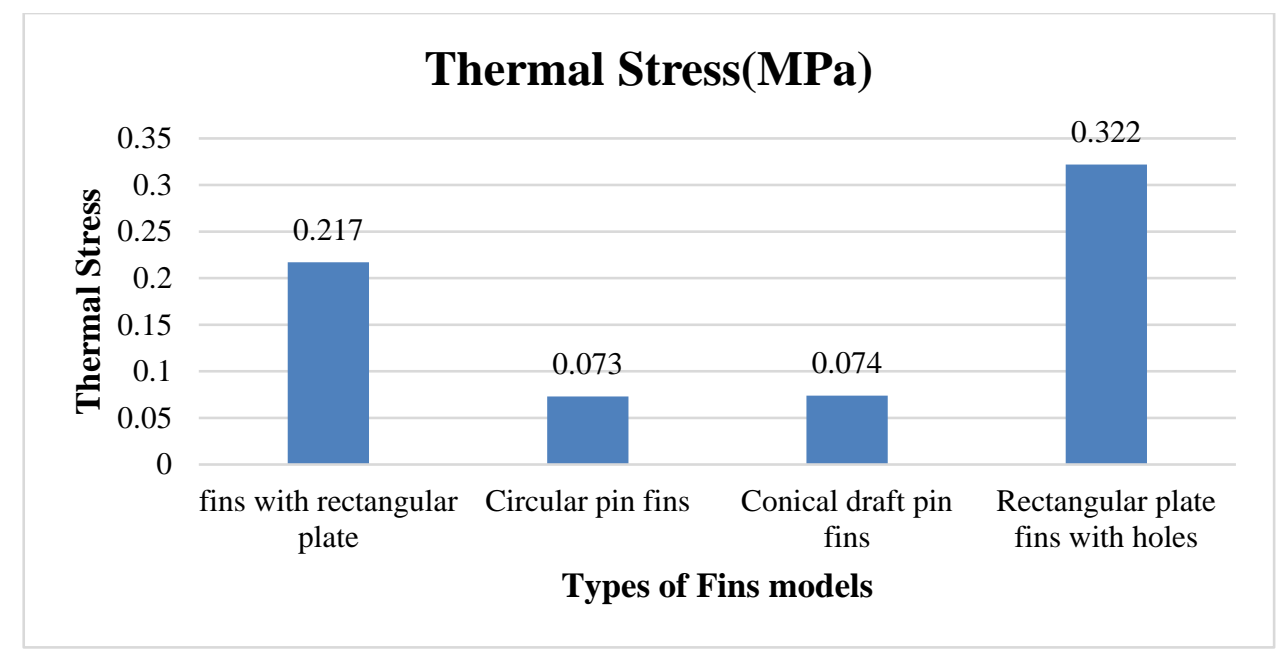

Figure 21: Comparison of Thermal Stresses of Fin Models

\section{CONCLUSION}

From the comparative analysis of plate Fins, Circular Pin fins, plate fins with holes, and draft Pin fins study conclusion is that the Total heat flux found maximum $0.016 \mathrm{~W} / \mathrm{mm}^{2}$ in Circular Pin fins. Maximum temperature found in Conical draft Pin Fins is $81.68^{\circ} \mathrm{C}$ and Minimum Temperature found in Plate Fins is $55.32{ }^{\circ} \mathrm{C}$. Maximum Temperature drop found on Conical draft pin fin $5.6{ }^{\circ} \mathrm{C}$ and minimum temperature drop found on plate fin is $1.72{ }^{\circ} \mathrm{C}$.

So, it is concluded that Pin Fins with Conical draft Pin Fins is shows better Heat transfer properties in this analysis. Thus, better heat transfer for fins or an experimental result shows that Conical draft Pin Fins having better than plate Fins. The overall analysis is performed on ANSYS FEM analysis Tool. Thus, further research can be carried with the advance materials and different designing, analysis tools. From the above study work the following conclusions are made:

- The thermal analysis of fins by modifying its certain parameters such as geometry and Plate fins and Pin fins has been completed.

- By observing the analysis results, we can easily say; using Conical draft Pin Fins with material Aluminum alloy 1060 is better since the temperature drop and the heat transfer rate in a Conical draft Pin Fins much more compared to Plate fins.

\section{REFERENCES}

[1] M. G. Sobamowo, G. A. Oguntala, A. A. Yinusa, "Nonlinear Transient Thermal Modeling and Analysis of a Convective-Radiative Fin with Functionally Graded Material in a Magnetic Environment", Hindawi, Modelling and Simulation in Engineering, Volume 2, 2019, 16 pages.

[2] K. Karthikeyan, C. Saravanan, T. Senthil Kumar, "Enhancement of Heat Transfer Analysis and Optimization of Engine Fins of Varying Geometry", International Journal of Trend in Scientific Research and Development", Volume - 2, Issue - 4, 2018.

[3] Mahendra Kumar Ahirwar, Ravindra Mohan, Gurjeet Singh, "International Research Journal of Engineering and Technology", Volume: 05, Issue: 01, Jan-2018.

[4] Deepak Tekhre, Jagdeesh Saini, "Design Modification and Thermal Analysis of IC Engine Fin", International Refereed Journal of Engineering and Science (IRJES), Volume 6, Issue $11,2017$. 
[5] Devendra J. Waghulde1, V H Patil, T. A. Koli,"Effect of Fin Thickness and Geometry on Engine Cylinder Fins", International Research Journal of Engineering and Technology (IRJET)", Volume: 04 Issue: 07, July -2017.

[6] K. Sathishkumar, K. Vignesh, N. Ugesh, P. B. Sanjeevaprasath, "Computational Analysis of Heat Transfer through Fins with Different Types of Notches", International Journal of Advanced Engineering Research and Science (IJAERS), Vol-4, Issue-2, Feb- 2017.

[7] Mayank Jain, Mahendra Sankhala, Kanhaiya Patidar, "heat transfer analysis and optimization of fins by Variation in geometry", International Journal of Mechanical and Production Engineering, Volume- 5, Issue-7, 2017.

[8] Ajay Jain, Advit Anand Saraswat, OP Shukla, "A Survey on Heat Transfer Of Air Cooled Internal Combustion Engine Various Fin Cutting Shape", International Research Journal of Engineering and Technology, Volume: 03, Issue: 02, Feb-2016.

[9] N.Srinivasa Rao1, G.V. Subhash2, K. Ashok Kumar, "Design and Study The Effectiveness Of Engine Cylinder Fin With Variable Geometry And Material", International Journal of Research in Engineering and Technology, Volume: 05, Issue: 10, 2016.

[10] R. Arularasan, P. Hemanandhan, T. Thamizhselvan, "Modelling and simulation of engine cylinder fins by using FEA", International Journal of Advanced Research, Volume 4, Issue 1, 2016.

[11] Mahendran.V, Venkatasalakumar.A, "Analysis of IC Engine Air Cooling Of Varying Geometry And Material", International Journal Of Engineering Sciences \& Research Technology, ISRA, 2015.

[12] Prem Prakash Pandit, P S Chauhan, "Unsteady Simulation of Rectangular Fin for Cooling of Automobile Engine", IRJMST, Vol 6, Issue 4, 2015.

[13] Mohsin A. Ali, S.M Kherde, "Design Modification and Analysis of Two-Wheeler Cooling Fins", International Journal of Advances in Engineering \& Technology, Vol. 7, Issue 3, July, 2014, pp. 998-1002.

[14] P. Sai Chaitanya, B. Suneela Rani, K. Vijaya Kumar, "Thermal Analysis of Engine Cylinder Fin by Varying Its Geometry and Material", IOSR Journal of Mechanical and Civil Engineering, Volume 11, Issue 6 Ver. I, 2014.

[15] Hardik D. Rathod, Ashish J. Modi, Pravin P. Rathod, "Effect of Different Variables on Heat Transfer Rate of Four-Stroke Si Engine Fins Review Study", International Journal of Mechanical Engineering and Technology (IJMET), Volume 4, Issue 2, 2013. 